\title{
Visualized Analysis on the Study of the International Spread of Chinese Language
}

\author{
Huixia Zhang ${ }^{1}$, Chunlin $\mathrm{Yao}^{2, *}$ \\ ${ }^{1}$ School of Foreign Languages, North China University of Science and Technology \\ ${ }^{2}$ School of Foreign Languages, Tianjin Chengjian University \\ ${ }^{*}$ Corresponding author. Email: yao_chunlin@126.com
}

\begin{abstract}
Based on 84 academic papers published in CNKI from 2006 to 2020 on the international spread of Chinese language, the study analyses the development of the study on the international spread of Chinese language in the past 15 years visualized with the software of CiteSpace. The research results are as follows: Researches on the nationalization of the international communication of Chinese grow rapidly; The amounts of journals related to the international spread of Chinese language are large, but core journals account for a small proportion; There are not many institutions that research the nationalization of Chinese international communication, and the support rate of national social science funds is low; Most of the researchers come from language colleges or normal colleges; The cooperation between scholars is rare and the academic team and position construction need to be strengthened; Countries in Southeast Asia and Central Asia are paid more attention to, and the research topics focus on the history of Chinese communication, Chinese teaching, Chinese communication strategies, the current situation of communication, and the international promotion of Chinese. Regarding the existing shortcomings, some suggestions are put forward to promote the development of research on the international communication of Chinese in my country.
\end{abstract}

Keywords: CiteSpace, globalization of Chinese, Nationalization, Visualized analysis.

\section{近十五年汉语国际国别传播可视化分析 \\ 张会霞 ${ }^{1}$, 姚春林 ${ }^{2, *}$}

1华北理工大学外国语学院唐山中国
${ }^{2}$ 天津城建大学外国语学院 天津 中国
${ }^{*}$ 通讯作者. 由阝箱: yao_chunlin@126.com

中文摘要

以中国知网2006-2020年发表的84篇汉语国际传播国别类的学术期刊论文为研究对象, 运用可视化分析法与文 献计量方法, 分析近15年汉语国际传播国别化研究取得的进展。研究表明: 汉语国际传播国别化研究经历了从 缓慢起步到快速增长的过程; 期刊分布种类广泛, 但是核心期刊占比较少; 研究汉语国际传播国别化的机构不 多, 国家级社会科学基金支持率低; 研究者群体较大, 多来自语言类与师范类院校, 但是学者之间合作少, 跨 院校合作更少, 学术队伍和阵地建设有待加强; 东南亚与中亚地区是研究热点, 研究内容集中于汉语传播史、 汉语教学、汉语传播策略、传播现状、汉语国际推广等方面。根据存在的不足本研究提出了促进我国汉语国际 传播国别化研究发展的建议。

关键词: CiteSpace，汉语国际传播，国别化，可视化分析 
国家与民族之间的交流与接触总是伴随着语言传 播。李宇明先生曾对语言现象传播的本质做了界定： A 民族的语言被 B 民族学习使用, A 民族的语言就传 播到 B 民族[1]。随着中国综合国力与国际地位的提高, 越来越多的国家与中国在政治、经济、文化等方面开 展合作交流。在国际合作交往中汉语得到传播。汉语 国际传播在逐步发展, 并且成为国内外专家学者研究 的热点领域。自 2004 年在首尔成立第一个海外孔子 学院以来, 汉语国际传播更是进入了一个快速发展的 时期。领域内第一本学术期刊《汉语国际传播》创刊 （2011），第一届汉语国际传播学术研讨会召开 （2012），“中国语文现代化学会汉语国际传播研究 分会” 成立 (2012）, 这些都是汉语国际传播领域的 大事件。自此以后, 学术阵地逐渐建立, 学术人才储 备量也在增加, 学术成果也在递增, 汉语国际传播已 经发展成为一个独立的研究领域。汉语国际传播领域 的研究内容具有广泛性与多元化的特点。吴应辉教授 曾将汉语国际传播分成了九大研究内容。其中, 汉语 国际传播国别化研究是其研究内容之一[2]。“国别化” 是视不同国家与地域的具体情况, 将其作为特征化的 研究样本的一种研究方法。即根据一国或一地域的不 同情况, 展开有针对性的研究。每个国家的情况不同, 汉语在当地的传播自然也就不同。本文运用 CiteSpace 这一新兴的科学技术手段, 对近十五年来的汉语国际 传播中的国别化研究进行梳理与分析, 以期厘清汉语 国际传播国别化研究的热点国家与地域, 探索汉语国 际传播国别化研究的动态与方向, 从而促进我国汉语 国际传播国别化研究的发展。

\section{1. 近十五年汉语国际传播国别化研究可视化 分析}

\section{1. 研究样本与数据来源}

研究样本与数据来自 2006-2020 年这十五年间中 国知网学术期刊, 具体获得方法如下: 在“检索条件” 一栏选择 “高级检索” , “主题”一栏输入 “汉语国 际传播”, 时间一栏设置为 “2000 年 1 月 1 日至 2020 年年 12 月 31 日” ，来源期刊设置成学术期刊, 共得 到 556 篇期刊论文文献, 对所得到的文献进行精确篮 选, 笁除新闻、会议等不相关文献, 最终得到 84 篇 汉语国际传播国别类有效文献。第一篇汉语国际传播 国别类文献发表于 2006 年, 所以本文研究近十五年 的发展成果。分析这 84 篇有效文献, 得到如下结论。

\section{2. 总体趋势分析}

数据显示, 2006-2012 年间共发文 10 篇, 年发文 量保持基本平稳; 2013-2019 年间共发文 74 篇, 年发 文量呈快速增长趋势, 是这一领域发展的高峰期; 2019 年达到顶峰, 年发文量 18 篇; 2020 年发文数量 略有下降, 发文量 12 篇。总体来说, 2006-2020 年汉 语国际传播国别类发文数量呈整体上升趋势。近 15 年的发文趋势具体见图 1。
普赖斯曾总结出文献指数增长规律: 学科发展初 级阶段, 文献发表数量稳定且少; 学科发展迅速阶段, 文献发表数量将以指数形式增长; 学科发展成熟阶段, 文献发表数量增长缓慢 $[3]$ 。从文献发文数量与学科发 展关系来看, 2006-2012 年发文数量较少, 可推断汉 语国际传播国别化研究发展处于不成熟的初步阶段; 2013-2020 年间发文数量较多且稳步增加, 可推断汉 语国际传播国别化研究进入了快速发展阶段。

引证数量与发文数量有所不同。2008-2019年引证 数量几乎呈指数增长趋势, 2008 年引证数量只有 4 篇, 2019 年引证数量高达 116 篇。2019 年以后开始 引证数量呈下降趋势。近 15 年的印证趋势具体见图 1 。

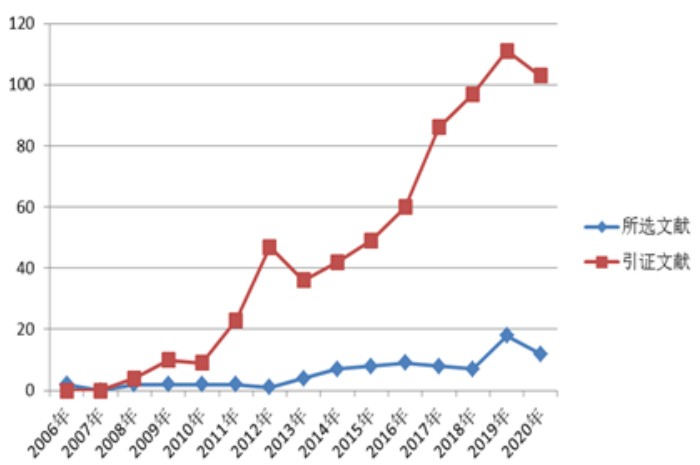

图 1 发文数量与引证数量趋势

\section{3. 发文期刊分布、机构分布、基金分布}

数据显示, 84 篇有效文献分布于 71 种期刊, 核心 期刊仅有三种, 分别为《海外华文教育》 《云南师范 大学学报》和《语言文字应用》。发表 3 篇及以上文 献的期刊有 5 种, 占总数的 $7 \%$, 其中《海外华文教 育》载文 5 篇, 《云南师范大学学报》载文 4 篇, 《汉 字文化》《语言文字应用》和《今传媒》各载文 3 篇。

在汉语国际传播国别化研究领域最活跃的两家机 构是北京语言大学与中央民族大学, 分别完成了 8 篇 论文, 占论文总篇数的 $19 \%$; 其次是云南民族大学, 该家单位完成了 6 篇论文, 占比为 $7 \%$ 。以上 3 家单 位完成的汉语国际国别传播的成果最多, 可看成国内 相关领域研究的核心力量。

一般来说, 某一学术领域的研究热点会获得较高 级别的基金支持。选定的 84 篇有效文献中，14篇文 献获得了国家社会科学基金的支持与资助, 占比为 16.7\%； 70 篇文献获得其他基金支持或无基金支持, 占比为 $83.3 \%$ 。有 16.7\%的成果获得国家级基金支持, 足见这一领域受社会重视程度。

\section{4. 文献互引网络、关键词共现网络、作者合 作网络}

通常情况下, 某一学者的文献被引频次与下载频 次越高, 该学者的在其所属科研领域的学术影响力就 越高。吴应辉与杨吉春在《世界汉语》期刊发表的《泰 
国汉语快速传播模式研究》[4]学术影响力较大, 在中 国知网的被下载次数为 4077 , 被引高达 264 次; 其次 为央青在《西南民族大学学报 (人文社会科学版) 》 发表的《泰国汉语快速传播对其他国家顶层设计的启 示》 [5]，在中国知网被下载801次，被引51次; 范晓 玲在《新疆社会科学》发表的《中亚地区汉语国际传 播现状与研究》[6] 在中国知网被下载955次, 被引40 次，其余文献的被引频次都在40次以下。

在CiteSpace可视化分析中, 关键词的词频反映了 某一研究领域的热点。一个词的出现频率越多, 这个 词就是某一专业研究领域的热点[7]。此次研究通过关 键词共现网络分析来探索出汉语国际传播国别化研 究领域的热点。具体操作方法如下: 笁选阈值设定时, 将出现频次设定为 $1-20$, 共现频次设为1-4。数据显示, 华文教育的词频为19; 语言传播、汉语传播的词频为 17 ; 文化传播的词频为 16 ; 汉语文化的词频为 13 ; 传 播现状的词频为 11 : 汉语教育的频次为 10 ; 对外汉语 教学的词频为 9 ; 国际推广与国家汉办的词频为 8 ; 国 际教育、汉语学习者、汉语专业等的词频为 7 ; 顶层 设计、传播史、中国文化、传播策略四个词的频次为 5。以上数据说明, 汉语国际传播研究集中于华文教 育、语言传播、汉语教育、汉语文化传播、汉语传播 史、汉语传播现状、汉语传播策略与汉语国际推广等 方面。在涉及到国别类词汇时, 中亚, 东南亚地区的 词频为 4 , 东盟、朝鲜、泰国, 韩国等的频次为 2 ; 说 明汉语国际传播国别化研究的国家主要是东南亚以 及中亚地区的国家。

学者对学术领域的研究是阶段性的, 进而形成一 系列的研究。有的专家研究同一学术领域会形成作者 合作网络。笁选阈值设定时, 将出现频次设定为 1-4, 共现频次设为 1-4。数据显示。作者合作网络节点较 多, 说明在 2006-2020 年这 15 年中很多学者研究汉语 国际国别化传播, 这些学者大多数来自语言类与师范 类高校, 比如北京语言大学、北京外国语大学、重庆 师范大学、沈阳师范大学等。其中发文次数较高的五 位作者是李宝贵、王建勤、郑通涛、杨刚、吴应辉。 我们可将这五位学者称为汉语国际传播国别化研究 的核心作者; 作者合作网络连线少, 说明论文发表大 多是独立完成, 合作完成的论文较少。有的学者节间 距离比较近, 说明这些学者之间有一定的合作, 如, 辽宁师范大学的李宝贵、刘家宁、于芳, 南宁师范大 学的刘振平、杨绪宁、宁家静, 中央民族大学的吴应 辉、肖顺良。也有很多学者为汉语国际传播国别化研 究的发展做出了贡献, 如刘娟、张荣建等。汉语国际 传播国别化研究作者合作网络具体见图 2。

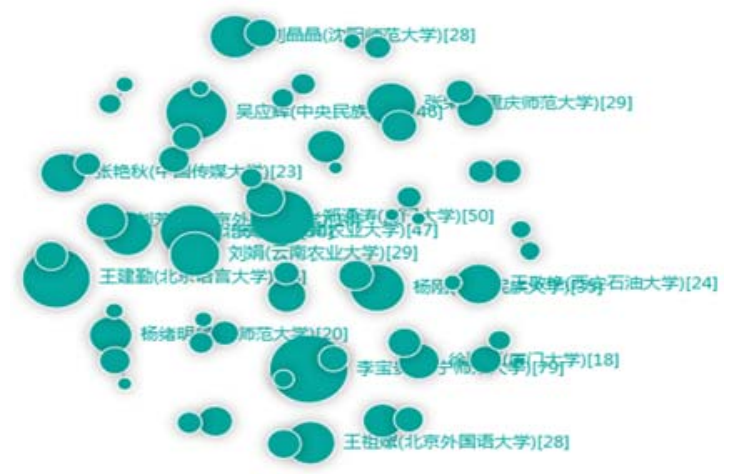

图 2 作者合作网络分析

\section{2. 讨论分析}

通过分析 84 篇来自中国知网的汉语国际传播国别 化研究文献, 了解到该学术领域的研究现状与研究发 展趋势。该学术领域的研究既有一些成就, 也存在一 些不足之处。

\section{1. 相关成就}

2006-2012 年间, 国内学者尚未意识到汉语国际传 播国别化研究的重要性; 2012 年以后相关学术成果发 表量一直增长。说明汉语国际传播国别化研究逐渐成 为一个热门研究领域; 从研究机构分布来看, 中央民 族大学与北京语言大学两所机构比较关注汉语国际 传播国别化这一领域的研究，其次是云南民族大学关 注汉语国际传播国别化这一领域的研究, 说明语言类 与民族类学校比较关注汉语国际传播国别化这一领 域的研究发展, 是汉语国际传播国别化领域研究的核 心团队; 从基金分布来看，国家社会科学基金支持部 分研究成果, 说明汉语国际传播国别化研究具有一定 的研究价值; 从文献互引网络与作者合作网络来看, 在汉语国际传播国别化研究领域最具权威性与学术 影响力的学者是吴应辉, 其他多数学者来自语言类和 师范类高校; 从关键词共现网络来看, 研究的国家主 要是东南亚与中亚地区的国家, 说明汉语在这些国家 传播状况良好; 研究热点集中于汉语传播策略、传播 史、传播现状等范围。通过以上分析可发现，我国在 汉语国际传播国别化领域的研究已取得了初步发展。

\section{2. 存在不足}

第一，汉语国际传播国别化研究的学科地位有待 进一步提高。该领域的发文数量一直呈上升趋势, 也 得到了学术界的关注, 但是我们仔细研究, 不难发现 以下几个细节: 2006-2020 年发表汉语国际传播国别 化研究论文 84 篇, 平均每年发文量 6 篇, 数目偏低; 国家社会科学基金支持的研究成果仅 14 篇, 数量略 少。

第二, 汉语国际传播国别化研究的载文期刊档次 低, 研究成果质量低。从发文期刊分布来看, 84 篇文 献来自 71 种期刊, 核心期刊载文占比 15\%, 说明汉 
语国际传播国别化研究的期刊种类少, 质量低, 论文 相对分散，不够集中。

第三，学者之间的合作较少，成熟的学术队伍与 阵地还未建成。虽然十五年间涌现出一大批关注汉语 国际传播国别化研究的学者, 也发表了一些论文, 但 是学者之间合发论文较少。即使他们有合作的研究成 果, 大多数也是来自同一院校, 跨院校合作较少。形 成的研究团队是同校内的, 学术队伍之间需要加强合 作与交流, 学术阵地需要加强建设。

第四，汉语国际传播国别化研究的国别种类不够 齐全。研究地区集中于东南亚与中亚的国家, 比如泰 国与塔吉克斯坦。

\section{3. 推进汉语国际传播国别化研究的建议}

2006 年以来, 汉语国际传播国别化研究取得了一 些成就, 但是存在的不足不能被忽视。针对这些不足 之处, 提出以下汉语国际传播国别化研究的建议。

第一, 提高汉语国际传播国别化研究的学科地位。 教育部门及相关机构应鼓励更多的学者投身汉语国 际传播国别化研究，支持学者发表高质量的研究成果。 对于有较高研究价值的汉语国际传播国别化研究课 题项目，加大扶持力度，加大资金支持。

第二, 严格把控期刊论文质量, 鼓励学者在高质 量期刊发表论文。高质量的期刊拥有高质量的研究成 果, 形成学术交流阵地, 吸引更多学者来此交流探讨, 有利于学科的进一步发展。

第三，学者之间加强交流与沟通, 培育汉语国际 传播国别化研究领域的学术队伍与阵地。很多学者处 于孤军奋斗的状态, 要跨院校合作, 相互交流, 相互 借鉴, 形成一批专业的汉语国际传播国别化研究领域 的学术队伍, 建立起汉语国际传播国别化研究领域的 学术阵地。

第四, 加大汉语国际传播国别研究范围。要拓宽 视野, 放眼全球, 不能将研究目光仅局限于东南亚与 中亚地区的国家。每个国家的情况不一样, 汉语传播 的具体情况也不同 [8]。各个国家的汉语国际传播都值 得关注和研究。只有加大汉语国际传播国别研究范围, 才能更好地促进汉语在全球的传播。

\section{REFERENCES}

[1] Li, Yuming. Exploring the law of language transmission: preface to Chinese education series for the world [J]. Journal of Yunnan Normal University (Teaching \& Studying Chinese as a Foreign Language Edition), 2007, 5(04):1-3. DOI:10.16802/j.cnki.ynsddw.2007.04.001

[2] $\mathrm{Wu}$, Yinghui. The Theories and Methods of the Study of Chinese Language Transmission [M]. Beijing: The Press of Minzu University of China, 2012.
[3] Ding, Xuedong. The Basic of Bibliometric [M]Beijing: Beijing University Press, 1993.

[4] Wu, Yinghui \& Yang, Jichun. On the mode for rapid promoting Chinese teaching in Thailand [J]. Chinese Teaching in the World, 2008, 22 (4): 125-132.

[5] Yang, Qing. The instruction of the rapid promoting the Chinese teaching in Thailand to other countries' foreign language teaching planning [J]. Journal of Southwest Minzu University (Humanities and Social Science), 2011, 32(02):55-59.

[6] Fan, Xiaoling. The situation and the study of Chinese international transmission in central-Asia area [J]. Social Sciences in Xinjiang, 2009, 29 (2): 46-48.

[7] Yao, Chunlin. The visualized study on the study of teachers' professional beliefs with the help of CiteSpace [J]. Journal of Luohe Vocational Technology College. 2020, 19 (4): 30-33. DOI:10.3969/j.issn.1671-7864.2020.04.009

[8] Yao, Min. Research status and thoughts on Chinese language spread [J]. Journal of Graduate School of Chinese Academy of Social Sciences, 2016, 38 (4):91-95. 